Pacific Journal of Mathematics

A DENSITY WHICH COUNTS MULTIPLICITY 


\title{
A DENSITY WHICH COUNTS MULTIPLICITY
}

\author{
ROBERT E. DRESSLER
}

P. Erdös, using analytic theorems, has proven the following results: Let $f(x)$ be the number of integers $m$ such that $\phi(m) \leqq x$, where $\phi$ is the Euler function, and let $g(x)$ be the number of integers $n$ such that $\sigma(n) \leqq x$, where $\sigma$ is the usual sum of divisors function. Then there are positive (but undetermined) constants $c_{1}$ and $c_{2}$ such that $f(x)=c_{1} x+o(x)$ and $g(x)=c_{2}(x)+o(x)$. The constants $c_{1}$ and $c_{2}$ can be calculated using complex analysis including the Wiener-Ikehara Theorem. A major purpose of this paper is to give an elementary proof that $\lim _{x \rightarrow \infty} f(x) / x$ exists and, in the process, calculate the value of the limit. These considerations of multiplicity motivate a generalization of natural density which counts multiplicity. This paper contains an investigation of this generalization.

Let $A=\left\{a_{i}\right\}_{i=1}^{\infty}$ be a sequence of positive real numbers $\geqq 1$. For a positive integer $j$, define $\#(A, j)$ to be the number of integers $i$ such that $a_{i} \leqq j$ (that is, the number of elements of $A$ counting multiplicity which are $\leqq j$ ). If $\lim \inf _{j \rightarrow \infty} \sharp(A, j) / j=\alpha$ (we allow $\alpha=\infty$ ) we say $A$ has $\Delta$-asymptotic density $\alpha$ and we define $\Delta(A)=\alpha$. We also define $\bar{\Delta}(A)=\lim \sup _{j \rightarrow \infty} \sharp(A, j) / j$. If $\underline{\Delta}(A)=\bar{\Delta}(A)$ we say $A$ has $\Delta$-natural density $\alpha$ and we define $\Delta(A)=\alpha$. It is clear that a reordering of $A$ does not affect $\triangle(A)$ or $\bar{\Delta}(A)$. It is also clear that $\underline{\Delta}(A)=\underline{\Delta}\left(\left\{\left[a_{i}\right]\right\}_{i=1}^{\infty}\right)$ and $\bar{\Delta}(A)=\bar{J}\left(\left\{\left[a_{i}\right]\right\}_{i=1}^{\infty}\right)$ where $\left[a_{i}\right]$ is the greatest integer which does not exceed $a_{i}$. Unless otherwise specified all sequences in this paper will be of positive real numbers.

Throughout this paper $d$ will denote natural density, i.e., the classical analog of $\Delta$ where multiplicity is not counted; $Z^{+}$will denote the set of positive integers; $Q^{+}$will denote the positive rational numbers; $R^{+}$will denote the set of positive real numbers; $p$ will always be a prime; and $P=\left\{p_{i}\right\}_{i=1}^{\infty}$ will be the sequence, in the natural order, of primes.

If $\gamma: Z^{+} \rightarrow R^{+}$then to $\gamma$ there corresponds the unique sequence $\gamma(1), \gamma(2), \cdots$. We will write $\gamma$ in place of this sequence. Thus, for example, in the notation of this paper $\Delta(\phi)$ and $\Delta(\sigma)$ exist and are positive [5]. If for instance $\gamma=\tau$, where $\tau(n)=$ the number of positive integer divisors of the positive integer $n$, then it is clear that $\Delta(\tau)=\infty$.

If $A=\left\{a_{i}\right\}_{i=1}^{\infty}$ and $B=\left\{b_{j}\right\}_{j=1}^{\infty}$ are sequences then define $A+B$ to be the sequence, in the natural order, of positive real numbers $x$ such that there exist $i$ and $j \in Z^{+}$with $a_{i}+b_{j}=x$, and $x$ appears in this 
sequence the precise number of distinct ways we can write $x=$ $a_{i_{1}}+b_{j_{1}}$. Note that it is possible to have $x=a_{i_{1}}+b_{j_{1}}$ and yet for $x$ not to be a member of $A+B$. This happens precisely when some positive number $y<x$ is representable infinitely often in the form $y=a_{i}+b_{j}$. Finally if $A$ and $B$ are sets of positive reals then define $A \backslash B$ to be the complement of $B$ in $A$.

1. Number theoretic functions. In this section we investigate the densities of certain sequences related to the $\phi$ function and other functions.

We first prove some lemmas which we will use to calculate $\Delta\left(\phi^{\prime}\right)$.

Definition 1.1. For each $n \in Z^{+}$and $k \in Z^{+}$define

$$
\phi_{k}(n)=n \prod_{\substack{p \mid n \\ p \subseteq p_{k}}} \frac{p-1}{p} ;
$$

cf. $[8$, p. 56].

Lemma 1.1.1. $\Delta\left(\phi_{k}\right)=\prod_{p \leqq p_{k}}(1+(1 / p(p-1)))$ for each $k \in Z^{+}$.

Proof. Pick $k \in Z^{+}$and define $P^{k}=\left\{p_{1}, p_{2}, \cdots, p_{k}\right\}$. To each subset $P_{j}^{k}\left(j=1,2, \cdots, 2^{k}\right)$ of $P^{k}$ there corresponds the sequence of positive integers which are divisible by each member of $P_{j}^{k}$ and by no member of $P^{k} \backslash P_{j}^{k}$. These sequences are pairwise disjoint and their union is $Z^{+}$.

For a subset $P_{j}^{k}$ of $P^{k}$ say $\left\{n_{j, i}\right\}_{i=1}^{\infty}$ is the corresponding sequence. It is clear that

$$
\#\left(\phi_{k}, n\right)=\sum_{j=1}^{2^{k}} \#\left(\left\{\phi_{k}\left(n_{j, i}\right)\right\}_{i=1}^{\infty}, n\right) \quad \text { for each } n \in Z^{+} .
$$

Now for a fixed $P_{j}^{k}$ the density of $\left\{n_{j, j}\right\}_{i=1}^{\infty}$ is clearly

$$
\prod_{p \in P_{j}^{k}} \frac{1}{p} \prod_{p \in P^{k} \backslash P_{j}^{k}} \frac{p-1}{p} .
$$

Also for each integer $m$ in this sequence we have

$$
\phi_{k}(m)=m \prod_{p \in P_{j}^{k}} \frac{p-1}{p} .
$$

Therefore

$$
\begin{aligned}
& \Delta\left(\left\{\phi_{k}(m)\right\}_{m} \text { in the sequence defined by } p_{j}^{k}\right) \\
= & \left(\prod_{p \in P_{j}^{k}} \frac{p}{p-1}\right)\left(\prod_{p \in P_{j}^{k}} \frac{1}{p}\right)\left(\prod_{p \in P^{k} \backslash P_{j}^{k}} \frac{p-1}{p}\right)=\prod_{p \in P_{j}^{k}} \frac{1}{p-1} \prod_{p \in P^{k} \backslash P_{j}^{k}} \frac{p-1}{p} .
\end{aligned}
$$


So by $(*)$ we have

$$
\begin{aligned}
\Delta\left(\phi_{k}\right) & =\sum_{j=1}^{2^{k}}\left(\prod_{p \in P_{j}^{k}} \frac{1}{p-1} \prod_{p \in P^{k} \backslash P_{j}^{k}} \frac{p-1}{p}\right) \\
& =\sum_{j=1}^{2^{k}} \frac{\prod_{p \in P^{k} P_{j}^{k}} \frac{(p-1)^{2}}{p}}{\prod_{p \in P^{k}}(p-1)}=\frac{\prod_{p \in P^{k}}\left(1+\frac{(p-1)^{2}}{p}\right)}{\prod_{p \in P_{k}^{k}}(p-1)}=\prod_{p \in P^{k}}\left(1+\frac{1}{p(p-1)}\right)
\end{aligned}
$$

and the lemma is proved.

Note. $\lim _{k \rightarrow \infty} \Delta\left(\phi_{k}\right)=\prod_{p \in P}\left(1+\frac{1}{p(p-1)}\right)<\infty$.

Lemma 1.1.2. Choose $n \in Z^{+}, n>1$, and say $r \in Z^{+}$satisfies $p_{1} p_{2} \cdots p_{r} \leqq n$. Then $\#\left(\phi_{r}, n\right) \leqq n\left(\Delta\left(\phi_{r}\right)+1\right)$. In fact if

$$
n=t p_{1} p_{2} \cdots p_{r}, t \geqq 1, t \in Q^{+},
$$

then $\#\left(\phi_{r}, n\right) \leqq n\left(\Delta\left(\phi_{r}\right)+1 / t\right)$.

Proof. Say $n=t p_{1} \cdots p_{r}(t \geqq 1)$. Then if

$$
P_{j}^{r}=\left\{q_{1}, \cdots, q_{s}\right\} \subset\left\{p_{1}, \cdots, p_{r}\right\}
$$

we have $R_{j, r} \stackrel{\text { def }}{=}$ the number of integers $m$ such that $\phi_{r}(m) \leqq n$ and $q_{1} \cdots q_{s} \mid m$ and none of the members of $P^{r} \backslash P_{j}^{r}$ divide $m=$ the number of integers $m \leqq n\left(q_{1} / q_{1}-1\right) \cdots\left(q_{s} / q_{s}-1\right)$ which are divisible by $q_{1} \cdots q_{s}$ and divisible by no member of $P^{r} / P_{j}^{r}$. Say $T_{j, r}$ is the smallest integer $\geqq t\left(q_{1} / q_{1}-1\right) \cdots\left(q_{s} / q_{s}-1\right)$. Then clearly $R_{j, r} \leqq$ the number of integers $m$ which do not exceed $p_{1} \cdots p_{r} T_{j, r}$ and which are divisible by $q_{1} \cdots q_{s}$ and divisible by no member of $P^{r} \backslash P_{j}^{r}$. But since $T_{j, r}$ is an integer we have

$$
\begin{aligned}
R_{j, r} & \leqq\left(p_{1} \cdots p_{r} T_{j, r}\right) \frac{1}{q_{1} \cdots q_{s}} \prod_{p \in P r \backslash P_{j}^{r}} \frac{p-1}{p} \\
& \leqq p_{1} \cdots p_{r}\left(t \frac{q_{1}}{q_{1}-1} \cdots \frac{q_{s}}{q_{s}-1}+1\right) \frac{1}{q_{1} \cdots q_{s}} \prod_{p \in P^{r} \backslash P_{j}^{r}} \frac{p-1}{p} .
\end{aligned}
$$

Now $\#\left(\phi_{r}, n\right)=\sum_{j=1}^{2 r} R_{j, r}$. So

$$
\begin{aligned}
\#\left(\phi_{r}, n\right) \leqq & \sum_{j=1}^{2^{r}}\left(p_{1} \cdots p_{r}\left(t \prod_{p \in P_{j}^{r}} \frac{p}{p-1}+1\right) \prod_{p \in P_{j}^{r}} \frac{1}{p_{p \in P r}} \prod_{p P_{j}^{r}} \frac{p-1}{p}\right) \\
= & t p_{1} \cdots p_{r} \sum_{j=1}^{2^{r}}\left(\prod_{p \in P_{j}^{r}} \frac{1}{p-1} \prod_{p \in P^{r} \backslash P_{j}^{r}} \frac{p-1}{p}\right) \\
& +p_{1} \cdots p_{r} \sum_{j=1}^{2^{r}}\left(\prod_{p \in P_{j}^{r}} \frac{1}{p_{p}} \prod_{p \in P \backslash P_{j}^{r}} \frac{p-1}{p}\right)=n\left(\Delta\left(\phi_{r}\right)+\frac{1}{t}\right)
\end{aligned}
$$


and the lemma is proved.

Lemma 1.1.3. Choose $n \in Z^{+}, n>1$, and say $r \in Z^{+}$is defined by $p_{1} \cdots p_{r} \leqq n<p_{1} \cdots p_{r+1}$. Then we have

$$
\dot{\phi}(m) \leqq n \Longrightarrow \phi_{r}(m) \leqq \frac{p_{r+1}}{p_{r+1}-1} \cdots \frac{p_{2 r+1}}{p_{2 r+1}-1} n .
$$

Thus

$$
\sharp(\phi, n) \leqq \#\left(\phi_{r},\left[\frac{p_{r+1}}{p_{r+1}-1} \cdots \frac{p_{2 r+1}}{p_{2 r+1}-1} n\right]\right) .
$$

Proof. Suppcse $m$ has more than $r+1$ distinct prime divisors. Then $\phi(m) \geqq\left(p_{r+2}-1\right)\left(p_{r+1}-1\right) \cdots\left(p_{1}-1\right) \geqq p_{1} \cdots p_{r+1}>n$, a contradiction. So $m$ has at most $r+1$ distinct prime divisors.

Now

$$
\dot{\phi}_{r}(m)=\dot{\phi}(m) \prod_{\substack{p \mid m \\ p>p_{r}}} \frac{p}{p-1} \leqq n \prod_{\substack{p \mid m \\ p>p_{r}}} \frac{p}{p-1} \leqq n \frac{p_{r+1}}{p_{r+1}-1} \cdots \frac{p_{2 r+1}}{p_{2 r+1}-1}
$$

since $m$ has at most $r+1$ distinct prime divisors and the lemma is proved.

Theorem 1.1.

$$
\Delta(\dot{\phi})=\prod_{p \in P}\left(1+\frac{1}{p(p-1)}\right)=\frac{\zeta(2) \cdot \zeta(3)}{\zeta(6)},
$$

where $\zeta$ denotes the Riemann Zeta function.

Proof. It is well known [7, p. 246] that $\zeta(s)=\prod_{p \in P}\left(1 / 1-p^{-s}\right)$ for $s>1$. Thus it follows that $\prod_{p \in P}(1+(1 / p(p-1)))=(\zeta(2) \cdot \zeta(3) / \zeta(6))$. So it only remains to show that $\Delta(\phi)=\prod_{p \in P}(1+(1 / p(p-1)))$.

For $r \in Z^{+}$let $g_{r}=\left(p_{r+1} / p_{r+1}-1\right) \cdots\left(p_{2 r+1} / p_{2 r+1}-1\right)$. It follows from Mertens' Theorem and Tchebychef's Theorem [7, pp. 351 and 9] that $\lim _{r \rightarrow \infty} g_{r}=1$. Choose $n \in Z^{+}, n>1$, and say $r \in Z^{+}$is defined by $p_{1} \cdots p_{r} \leqq n=t p_{1} \cdots p_{r}<p_{1} p_{2} \cdots p_{r+1}$, where $t \geqq 1$.

Now, $\sharp\left(\phi_{r}, n\right)=\#\left(\dot{\phi}_{r-1}, n\right)+\left(\#\left(\phi_{r}, n\right)-\#\left(\phi_{r-1}, n\right)\right)$. But

$$
\#\left(\phi_{r}, n\right)-\#\left(\dot{\phi}_{r-1}, n\right)
$$

is the number of integers $m$ such that $p_{r} \mid m$ and

$$
n<\phi_{r-1}(m) \leqq \frac{p_{r}}{p_{r-1}} n .
$$

This number is the sum (over $j=1,2, \cdots, 2^{r-1}$ ) of the number of integers less than or equal to 


$$
\left(\prod_{p \in P_{j}^{r-1}} \frac{p}{p-1}\right) \frac{n p_{r}}{p_{r}-1}
$$

and greater than

$$
\left(\prod_{p \in P_{j}^{r-1}} \frac{p}{p-1}\right) n
$$

which are divisible by $p_{r}$ and each $p \in P_{j}^{r-1}$ and not divisible by any $p \in P^{r-1} \backslash P_{j}^{r-1}$. It then follows that

$$
\begin{aligned}
& \sharp\left(\phi_{r}, n\right)-\#\left(\phi_{r-1}, n\right) \\
\leqq & \sum_{j=1}^{2^{r-1}}\left\{\left(\frac{2 n p_{r}}{p_{r}\left(p_{r}-1\right)}\left(\prod_{p \in P_{j}^{r-1}} \frac{p}{p-1}\right)-\frac{n}{2 p_{r}}\left(\prod_{p \in P_{j}^{r-1}} \frac{p}{p-1}\right)\right)\right. \\
& \left.\times \prod_{p \in P_{j}^{r-1}} \frac{1}{p_{p \in P}} \prod_{r-1 \backslash P_{j}^{r-1}} \frac{p-1}{p}\right\}=n \Delta\left(\phi_{r-1}\right)\left(\frac{2}{p_{r}-1}-\frac{1}{2 p_{r}}\right)=o(n) .
\end{aligned}
$$

So $\#\left(\phi_{r}, n\right)=\#\left(\phi_{r-1}, n\right)+o(n)$.

By Lemma 1.1.2 we have

$$
\sharp\left(\phi_{r-1}, n\right) \leqq n\left(\Delta\left(\phi_{r-1}\right)+\frac{1}{p_{r}}\right)=n \Delta\left(\phi_{r}\right)+o(n) .
$$

So $\#\left(\phi_{r}, n\right) \leqq n \Delta\left(\phi_{r}\right)+o(n)$. By Lemma 1.1.3 we have $\sharp(\phi, n) \leqq \#\left(\phi_{r}\left[g_{r} n\right]\right)$. So $\#(\phi, n) \leqq\left[g_{r} n\right] \Delta\left(\phi_{r}\right)+o\left(\left[g_{r} n\right]\right)=n \Delta\left(\phi_{r}\right)+o(n)$. Divide by $n$ and let $n \rightarrow \infty$ to get $\overline{\lim }_{n \rightarrow \infty} \sharp(\phi, n) / n \leqq \lim _{r \rightarrow \infty} \Delta\left(\phi_{r}\right)$.

Finally $\underline{\Delta}(\phi) \geqq \lim _{k \rightarrow \infty} \Delta\left(\phi_{k}\right)$ because if we choose $k \in Z^{+}$then for $n$ large we have $\sharp(\phi, n) \geqq \sharp\left(\phi_{k}, n\right) \geqq n\left(\Delta\left(\phi_{k}\right)-1 / k\right)$ and so

$$
\lim \inf _{n \rightarrow \infty} \sharp(\phi, n) / n \geqq \Delta\left(\phi_{k}\right)-1 / k
$$

for each $k \in Z^{+}$. Thus $\Delta(\phi)=\lim _{r \rightarrow \infty} \Delta\left(\phi_{r}\right)=\prod_{p \in P}(1+(1 / p(p-1))$ and the theorem is proved.

A related result due to $P$. Erdös may be found in $[4$, pp. 211213].

DEFINITION 1.2. For $t \geqq 1$, $t$ a real number, a positive integer $n$ is said to be $t$-abundant if $\sigma(n) \geqq t n$.

H. Davenport [3] has shown that for $t$ as above, the sequence of $t$-abundant positive integers has a natural density.

THEOREM 1.2. For each $k \in Z^{+}$let $d_{k}=$ the natural density of the k-abundant integers. Then $\sum_{k=1}^{\infty} d_{k} \leqq \Delta(\phi)=(\zeta(2) \cdot \zeta(3) / \zeta(6))$.

Proof. It is known that $\phi(n) \sigma(n) / n^{2}<1$ for each integer $n>1$ 
[7, p. 267]. So if $n \in](k-1) N, k N]$ and $\sigma(n) \geqq k n$ then $\phi(n) \leqq N$. Thus for $k \in Z^{+}$and for $N$ large, depending on $k$, we have

$$
\begin{aligned}
\#(\phi, N) \geqq & N+d_{2}(2 N-N)+d_{3}(3 N-2 N)+\cdots \\
& +d_{k}(k N-(k-1) N)-\frac{N}{k} \\
= & N\left(1+d_{2}+d_{3}+\cdots+d_{k}-1 / k\right) \\
= & N\left(d_{1}+d_{2}+\cdots+d_{k}-1 / k\right)
\end{aligned}
$$

Now divide by $N$ and let $N \rightarrow \infty$. We then have

$$
\Delta(\phi) \geqq \lim _{k \rightarrow \infty}\left(d_{1}+d_{2}+\cdots+d_{k}-1 / k\right)=\sum_{k=1}^{\infty} d_{k}
$$

and the theorem is proved.

2. General theorems. We begin this section by stating some results whose proofs are not difficult.

1. If $A=\left\{a_{i}\right\}_{i=1}^{\infty}$ is a sequence such that $\Delta(A)=\infty$ then there exists a sequence $\left\{i_{j}\right\}_{j=1}^{\infty}$ of positive integers with $\sum_{j=1}^{\infty} a_{i_{j}} / i_{j}<\infty$.

2. If $A=\left\{a_{i}\right\}_{i=1}^{\infty}$ is a sequence such that $\Delta(A)=0$ then $\sum_{a_{i} \leqq r} a_{i}=$ $o\left(r^{2}\right)$ and $\sum_{a_{i} \leqq r} 1 / a_{i}=o(\log r)$.

3. If $A=\left\{a_{i}\right\}_{i=1}^{\infty}$ is a sequence such that $\infty>\Delta(A)>0$ then $\sum_{a_{i} \leqq r} a_{i} \sim \Delta(A) r^{2} / 2$ and $\sum_{a_{i} \leqq r} 1 / a_{i} \sim \Delta(A) \log r$.

THEOREM 2.1. Let $A=\left\{a_{i}\right\}_{i=1}^{\infty}$ be a sequence such that $\Delta(A)=\infty$. Then there exists a strictly increasing sequence $\left\{i_{j}\right\}_{j=1}^{\infty}$ of positive integers with $d\left(\left\{i_{j}\right\}_{j=1}^{\infty}\right)=0$ and $\Delta\left(\left\{a_{i_{j}}\right\}_{j=1}^{\infty}\right)=\infty$.

Proof. It suffices to assume $\lim _{i \rightarrow \infty} a_{i}=\infty$ because otherwise the proof is immediate.

Case I. $a_{1} \leqq a_{2} \leqq a_{3} \leqq \cdots$.

First, there is no loss of generality in supposing $a_{1}<a_{2}<a_{3}<\cdots$ because if $a_{i}=a_{i+1}=\cdots=a_{i+r-1}<a_{i+r}$ for some $i$ then define

$$
\varepsilon=\min \left(a_{i+r}-a_{i}, \begin{array}{l}
\text { the distance from } a_{i} \text { to the } \\
\text { smallest integer greater than } a_{i}
\end{array}\right)
$$

and replace $a_{i+t}$ by $a_{i}+t \varepsilon / r$ for $t=0,1, \cdots, r-1$.

We now define a subsequence $B$ of $A$ by induction. Let $a_{1} \in B$. If each of $a_{1}, a_{2}, \cdots, a_{k-1}$ has already been either included in $B$ or excluded from $B$, place $a_{k}$ in $B$ if

$$
\frac{\#\left(B, a_{k-1}\right)+1}{a_{k}} \leqq \sqrt{\frac{\#\left(A, a_{k}\right)}{a_{k}}}
$$


and exclude $a_{k}$ from $B$ if the inequality fails. It then follows that $\#\left(B, a_{k}\right) / a_{k} \sim \sqrt{\#\left(A, a_{k}\right) / a_{k}}$ and so $\Delta(B)=\infty$. Also if we write $B=$ $\left\{a_{i_{j}}\right\}_{j=1}^{\infty}$ then we have $d\left(\left\{i_{j}\right\}_{j=1}^{\infty}\right)=0$ because

$$
\begin{aligned}
\frac{n}{i_{n}} & =\frac{\#\left(\left\{i_{j}\right\}_{j=1}^{\infty}, i_{n}\right)}{i_{n}}=\frac{\#\left(B, a_{i_{n}}\right)}{\#\left(A, a_{i_{n}}\right)}=\frac{a_{i_{n}}}{\#\left(A, a_{i_{n}}\right)} \frac{\#\left(B, a_{i_{n}}\right)}{a_{i_{n}}} \\
& \sim \sqrt{\frac{a_{i_{n}}}{\#\left(A, a_{i_{n}}\right)}}\left(\sqrt{\frac{a_{i_{n}}}{\#\left(A, a_{i_{n}}\right)}} \frac{\#\left(B, a_{i_{n}}\right)}{a_{i_{n}}}\right)
\end{aligned}
$$

which tends to $0.1=0$ as $n \rightarrow \infty$.

Case II. We make no assumptions about the monotonicity of $A$. However, without loss of generality, we may still assume $a_{i}=a_{j} \Rightarrow$ $i=j$, for we can always order $A$ by size, deal with $A$ as in Case I, and then apply the inverse of the permutation used to order $A$ to the new sequence which is derived from $A$ by use of the $\varepsilon$ 's.

Now order $A$ by size and call this sequence $A^{*}=\left\{a_{i}^{*}\right\}_{i=1}^{\infty}$. We have $a_{i}^{*}<a_{i+1}^{*}$ for all $i \in Z^{+}$. It follows immediately that if any $n-1$ elements are deleted from $A$ the minimum of the remaining elements is $\leqq a_{n}^{*}$. It is also clear that if $A_{1}^{*}=\left\{a_{2 i-1}\right\}_{i=1}^{\infty}$ then $\Delta\left(A_{1}^{*}\right)=\infty$.

Apply Case I to $A^{*}$ to get a subsequence $B^{*}=\left\{a_{i_{j}}^{*}\right\}_{j=1}^{\infty}$ of $A^{*}$ such that $\Delta\left(B^{*}\right)=\infty$ and $d\left(\left\{i_{j}\right\}_{j=1}^{\infty}\right)=0$. Now define $t_{1}$ by $a_{t_{1}}=$ $\min \left(\left\{a_{i_{1}}, a_{i_{1}+1}, a_{i_{1}+2}, \cdots\right\}\right)$. It follows that $t_{1} \geqq i_{1}$ and $a_{t_{1}} \leqq a_{i_{1}}^{*}$. Define $t_{2}$ by $a_{t_{2}}=\min \left(\left\{a_{i_{2}}, a_{i_{2}+1}, a_{i_{2}+2}, \cdots\right\} \backslash\left\{a_{t_{1}}\right\}\right)$. It follows that $t_{2} \geqq i_{2}$ and $a_{t_{2}} \leqq a_{i_{2}+1}^{*}$. In general define $t_{j}$ by

$$
a_{t_{j}}=\min \left(\left\{a_{i_{j}}, a_{i_{j+1}}, a_{i_{j}+2}, \cdots\right\} \backslash\left\{a_{t_{1}}, a_{t_{2}}, \cdots, a_{t_{j-1}}\right\}\right) \text {. }
$$

It follows that $t_{j} \geqq i_{j}$ and $a_{t_{j}} \leqq a_{i_{j}+j-1}^{*}$.

Since $t_{j} \geqq i_{j}$ for all $j \in Z^{+}$, it follows that $d\left(\left\{t_{j}\right\}_{j=1}^{\infty}\right)=0$. Also $\Delta\left(\left\{a_{i j}^{*}\right\}_{j=1}^{\infty}\right)=\infty$ so $\Delta\left(\left\{a_{i_{2 j-1}}^{*}\right\}_{j=1}^{\infty}\right)=\infty$ so $\Delta\left(\left\{a_{i_{j}+j-1}^{*}\right\}_{j=1}^{\infty}\right)=\infty$. It then follows that $A\left(\left\{a_{t_{j}}\right\}_{j=1}^{\infty}\right)=\infty$ and the theorem is proved.

To emphasize that care must be taken in the choice of $\left\{i_{j}\right\}_{j=1}^{\infty}$ in the above theorem we note the following result.

THEOREM 2.2. Suppose $\left\{i_{j}\right\}_{j=1}^{\infty}$ is a sequence of positive integers such that $d\left(\left\{i_{j}\right\}_{j=1}^{\infty}\right)=0$. Then there exists a strictly increasing sequence $A=\left\{a_{i}\right\}_{i=1}^{\infty}$ such that $\lim _{i \rightarrow \infty} a_{i}=\infty, \Delta(A)=\infty$, and $\Delta\left(\left\{a_{i_{j}}\right\}_{j=1}^{\infty}\right)=0$.

THeOREM 2.3. For each number $\alpha$ such that $0 \leqq \alpha \leqq \infty$ there exist two sequences $A$ and $B$ such that $\Delta(A)=\Delta(B)=0$ and $\Delta(A+B)=\alpha$.

Proof. If $\alpha=0$ choose $A=B$ to be the sequence of factorials. 
If $\alpha=\infty$ choose $A=B=P$. Then by the Prime Number Theorem $\Delta(A+B)=\infty$.

Suppose $0<\alpha<\infty$. Choose $\beta$ and $\gamma \in R^{+}$so that $(1 / 4) \pi \beta \gamma=\alpha$. Let $A=\left\{n^{2} / \beta^{2}\right\}_{n=1}^{\infty}$ and $B=\left\{n^{2} / \gamma^{2}\right\}_{n=1}^{\infty}$. Clearly $\Delta(A)=0=\Delta(B)$. Also, the number of elements in $A+B$ which are $\leqq n$ is the number of lattice points $(k, m)$ in the positive quadrant of the ellipse

$$
k^{2} / \beta^{2}+m^{2} / \gamma^{2} \leqq n
$$

This number is $(1 / 4) \pi \beta \gamma n+O(\sqrt{n})$. Thus $\Delta(A+B)=(1 / 4) \pi \beta \gamma=\alpha$ and the theorem is proved.

I wish to thank the referee for his helpful comments and in particular for his proof of Theorem 2.3 which is shorter than mine.

\section{BIBLIOGRAPHY}

1. F. V. Atkinson and Lord Cherwell, The mean values of arithmetical functions, Quart. J. Math., Oxford Series, 20 (1949), 65-79

2. R. Ayoub, An Introduction to the analytic theory of numbers, American Mathematical Society, Providence, 1963.

3. H. Davenport, Über Numeri Abundantes, Preuss. Akad. Wiss. Sitzungsber 2629 (1933), 147-151.

4. P. Erdös, On the normal number of prime factors of $p-1$ and some related problems concerning Euler's $\phi$-function, Quart. J. Math., Oxford Series, 6 (1935), 205-213. 5 . - Some remarks on Euler's $\phi$-function and some related problems, Bull. Amer. Math. Soc. 51 (1945), 540-544.

6. H. Halberstam and K. F. Roth, Sequences, Vol. I, Oxford Univ. Press, Oxford, 1966.

7. G. H. Hardy and E. M. Wright, An introduction to the theory of numbers, Oxford Univ. Press, Oxford, fourth edition, 1960.

8. M. Kac, Statistical independence in probability analysis and number theory, Carus Monograph, no. 12, The Mathematical Association of America, 1959.

9. E. Landau, Vorlesungen Über Zahlentheorie, Band 1, S. Hirzel, Leipzig, 1927.

10. W. Le Veque, Topics in number theory, Vol. 1, Addison Wesley, Reading, 1956.

11. I. Niven, The asymptotic density of sequences, Bull. Amer. Math. Soc. 57 (1951), 420-434.

12. I. Niven and H. S. Zuckerman, An Introduction to the theory of numbers, John Wiley and Sons, New York, 1960.

Received May 13, 1969. This work, part of my $\mathrm{Ph}$. D. thesis at the University of Oregon, was supported in part by N. D. E. A. Fellowship $¥ 65-02301$ and in part by N. S. F. Grant GP 6510.

UNIVERSITY OF OREGON 


\title{
PACIFIC JOURNAL OF MATHEMATICS
}

\author{
EDITORS
}

\author{
H. SAMELSON \\ Stanford University \\ Stanford, California 94305 \\ RichaRd PIERCE \\ University of Washington \\ Seattle, Washington 98105
}

J. DugundJI

Department of Mathematics

University of Southern California

Los Angeles, California 9.0007

RICHARD ARENS

University of California

Los Angeles, California 9.0024

\section{ASSOCIATE EDITORS}

E. F. BeCKenBACH
B. H. NeumanN

F. WoLE

K. YoSHIDA

\section{SUPPORTING INSTITUTIONS}

\author{
UNIVERSITY OF BRITISH COLUMBIA \\ CALIFORNIA INSTITUTE OF TECHNOLOGY \\ UNIVERSITY OF CALIFORNIA \\ MONTANA STATE UNIVERSITY \\ UNIVERSITY OF NEVADA \\ NEW MEXICO STATE UNIVERSITY \\ OREGON STATE UNIVERSITY \\ UNIVERSITY OF OREGON \\ OSAKA UNIVERSITY \\ UNIVERSITY OF SOUTHERN CALIFORNIA
}

\author{
STANFORD UNIVERSITY \\ UNIVERSITY OF TOKYO \\ UNIVERSITY OF UTAH \\ WASHINGTON STATE UNIVERSITY \\ UNIVERSITY OF WASHINGTON \\ AMERICAN MATHEMATICAL SOCIETY \\ CHEVRON RESEARCH CORPORATION \\ TRW SYSTEMS \\ NAVAL WEAPONS CENTER
}

The Supporting Institutions listed above contribute to the cost of publication of this Journal, but they are not owners or publishers and have no responsibility for its content or policies.

Mathematical papers intended for publication in the Pacific Journal of Mathematics should be in typed form or offset-reproduced, (not dittoed), double spaced with large margins. Underline Greek letters in red, German in green, and script in blue. The first paragraph or two must be capable of being used separately as a synopsis of the entire paper. The editorial "we" must not be used in the synopsis, and items of the bibliography should not be cited there unless absolutely necessary, in which case they must be identified by author and Journal, rather than by item number. Manuscripts, in duplicate if possible, may be sent to any one of the four editors. Please classify according to the scheme of Math. Rev. Index to Vol. 39. All other communications to the editors should be addressed to the managing editor, Richard Arens, University of California, Los Angeles, California, 90024.

50 reprints are provided free for each article; additional copies may be obtained at cost in multiples of 50 .

The Pacific Journal of Mathematics is published monthly. Effective with Volume 16 the price per volume (3 numbers) is $\$ 8.00$; single issues, $\$ 3.00$. Special price for current issues to individual faculty members of supporting institutions and to individual members of the American Mathematical Society: $\$ 4.00$ per volume; single issues $\$ 1.50$. Back numbers are available.

Subscriptions, orders for back numbers, and changes of address should be sent to Pacific Journal of Mathematics, 103 Highland Boulevard, Berkeley, California, 94708.

PUBLISHED BY PACIFIC JOURNAL OF MATHEMATICS, A NON-PROFIT CORPORATION

Printed at Kokusai Bunken Insatsusha (International Academic Printing Co., Ltd.), 7-17, Fujimi 2-chome, Chiyoda-ku, Tokyo, Japan. 


\section{Pacific Journal of Mathematics}

\section{Vol. 34, No. $2 \quad$ June, 1970}

Shair Ahmad, On the oscillation of solutions of a class of linear fourth order

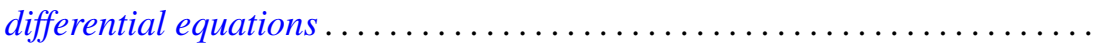

Leonard Asimow and Alan John Ellis, Facial decomposition of linearly

compact simplexes and separation of functions on cones ..............

Kirby Alan Baker and Albert Robert Stralka, Compact, distributive lattices of

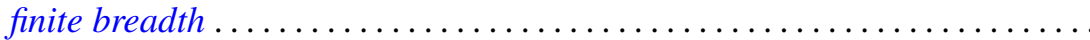

James W. Cannon, Sets which can be missed by side approximations to

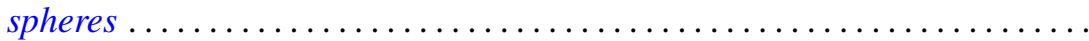

Prem Chandra, Absolute summability by Riesz means .................. 335

Francis T. Christoph, Free topological semigroups and embedding topological semigroups in topological groups....

Henry Bruce Cohen and Francis E. Sullivan, Projecting onto cycles in smooth, reflexive Banach spaces.................................

John Dauns, Power series semigroup rings .......................

Robert E. Dressler, A density which counts multiplicity ................

Kent Ralph Fuller, Primary rings and double centralizers ................

Gary Allen Gislason, On the existence question for a family of products.......

Alan Stuart Gleit, On the structure topology of simplex spaces .............

William R. Gordon and Marvin David Marcus, An analysis of equality in

certain matrix inequalities. $I \ldots \ldots \ldots \ldots \ldots \ldots \ldots \ldots$

Gerald William Johnson and David Lee Skoug, Operator-valued Feynman

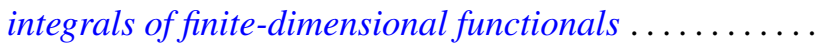

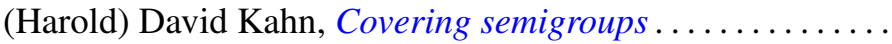

Keith Milo Kendig, Fibrations of analytic varieties

Norman Yeomans Luther, Weak denseness of nonatomic measures on perfect,

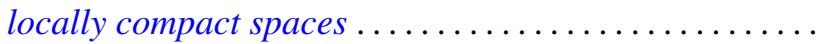

Guillermo Owen, The four-person constant-sum games; Discriminatory solutions on the main diagonal ...

Stephen Parrott, Unitary dilations for commuting contractions

Roy Martin Rakestraw, Extremal elements of the convex cone $A_{n}$ of

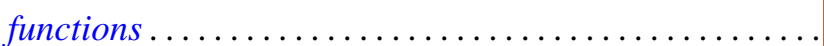

Peter Lewis Renz, Intersection representations of graphs by

William Henry Ruckle, Representation and series summability of complete

biorthogonal sequences.

F. Dennis Sentilles, The strict topology on bounded sets ...

Saharon Shelah, A note on Hanf numbers ...

Harold Simmons, The solution of a decision problem for several classes of rings. . .

Kenneth S. Williams, Finite transformation formulae involving the Legendre 